\title{
A Practical Approach to Indoor Air Quality for Municipal Public Health and Safety
}

\author{
Nathan J. Edwards, Brian Colder, Jon Sullivan, Laura Naramore \\ The MITRE Corporation, McLean, VA, USA \\ Email: nedwards@mitre.org
}

How to cite this paper: Edwards, N. J., Colder, B., Sullivan, J., \& Naramore, L. (2021). A Practical Approach to Indoor Air Quality for Municipal Public Health and Safety. Open Journal of Political Science, 11, 176-191. https://doi.org/10.4236/ojps.2021.111012

Received: December 13, 2020

Accepted: January 26, 2021

Published: January 29, 2021

Copyright $\odot 2021$ by author(s) and Scientific Research Publishing Inc. This work is licensed under the Creative Commons Attribution International License (CC BY 4.0).

http://creativecommons.org/licenses/by/4.0/

\begin{abstract}
Airborne contaminants from viral pathogens, biological weapons, wildfires, industrial accidents, and other sources present a complex policy and technology challenge for the public sector health and safety. During the global pandemic that began in early 2020, indoor air quality has become a focal point for companies and communities who seek affordable, technically sound processes to evaluate and mitigate threats to air quality in their work environments. This paper provides an overview of methods derived from observations of more than 190 scientific experiments to evaluate indoor air quality effects from wearing face masks and in public transportation vehicles. The methods can be adapted for locally administered indoor air quality programs, including high-risk environments such as nursing homes, schools, office areas, and public transportation. The approach follows an Occupational Health and Safety Administration (OSHA) hazards-control process and includes surveys, analysis and decisions based on science and mitigation selection, as well as a detailed description of implementing reduced-cost field testing.
\end{abstract}

\section{Keywords}

Indoor Air Quality, Public Health, Urban Environmental Management, Airborne Transmission, Airborne Particle Dispersion

\section{Introduction}

Indoor air quality (IAQ) has become a focal point for public health during the SARS-CoV-2 (COVID-19) pandemic which began in 2020. Companies and communities have had to take quick action while considering the cost-benefits of safe processes to evaluate and maintain healthy air quality for indoor occupancy environments. Aside from the acute threat of airborne infectious disease, healthy indoor air quality has always been desirable for population health, comfort, and in productive work environments. IAQ contaminants are commonly associated 
with headaches, fatigue, dizziness, and sinus irritation, while some airborne pollutants can also cause asthma, radon poisoning, mesothelioma, and asbestosis (U.S. EPA, 2016b). Common airborne contaminants include airborne infectious pathogens, organic and inorganic gases (e.g., carbon monoxide and radon), water vapors, noxious odors, and particulate matter (e.g., pollen and asbestos) that are generated from the natural environment as well as from wildfires, industrial byproducts, and other sources.

Of immediate and widespread concern, aerosolized biological particles carry pathogens which transmit contagious diseases through indoor air. Cold weather that relocates human activity to heated indoor spaces is a key factor of the seasonal morbidity patterns seen in respiratory illnesses, such as colds and the flu (Acharya \& Thapa, 2016). Aerosolized particles are known to be one key mode of COVID-19 transmission (Charlotte, 2020; Guenther et al., 2020; Hamner, 2020) as well as other respiratory diseases such as measles or tuberculosis. Contact tracing has revealed instances of COVID-19 disease transmission over long distances in indoor spaces, indicating that aerosolized virions can pollute large spaces (Kwon et al., 2020). Therefore, practical methods to evaluate and design changes to IAQ is an important tool to reduce levels of airborne infectious pathogens (including seasonal cold and flu) and continue to positively impact future levels of general population health, comfort, and performance.

Many U.S. government agencies and departments provide guidance on how to improve indoor air quality for the health and safety of people (OSHA, 2020; U.S. CDC \& U.S. HUD, 2006; U.S. EPA, 2014b; Weekes et al., 2020), but these sources of information are not coordinated. This makes practical application of the various indoor air quality management tools more difficult. Over the course of the current pandemic, many additional pandemic-specific tools have been developed to help individuals and organizations understand the risk of disease transmission in enclosed air spaces (Jimenez, 2020; Khan et al., 2020; Schimmoller et al., 2020). However, these applications are challenging to use by a generalist, and the underlying models and decision structures may be difficult to adapt to the specific circumstances of unique user concerns.

The current paper complements existing U.S. Government guidance and integrates existing airborne pathogen risk models with lessons learned from over 190 scientific experiments on indoor air quality with face masks and in public transportation vehicles. We provide a practical approach for local implementation of indoor air quality programs at high-risk facilities or environments such as nursing homes, schools, office areas, and on public transportation. The approach follows an OSHA hazards control process and includes surveys, analysis and decisions based on science and mitigation selection as well as a detailed description of reduced-cost field testing.

\section{Understanding of Engineering Controls and Human Factors}

When dealing with any human health hazard, the Occupational Safety and 
Health Administration (OSHA) Hazard Prevention and Control Guidelines recommends first attempting to eliminate or control the hazard with engineering solutions (OSHA, 2016). One of the key reasons why engineering solutions are preferred as the primary control is that these types of interventions reduce the dependency on human factors, which are notoriously vulnerable to consequential failure. Human factors are those conditions that if not managed correctly can result in human error. A study of maritime incidents (Schröder-Hinrichs et al., 2011), for example, found that individual human factor errors were reported as the root cause of incidents to an even greater extent than expected. Likewise, administrative controls which depend on humans not making errors will always fail eventually (Snell, 2015).

A healthcare pandemic example of the human factors fail-point has been revealed through contact tracing. Studies have found that outbreaks are often triggered when individuals are exposed outside of their workplaces and then fail to properly implement the explicit workplace controls and policies to prevent disease transmission (Simmons-Duffin, 2020). In contrast, a pandemic example of an engineering control is physically locking a workplace window in the open position to increase ventilation; the window cannot close itself. However, a human factor control requires a worker to wear a mask and limit person to person conversation, yet an individual may make an exception to talk to a friend or lower their face mask beneath their nose for comfort.

The OSHA Hierarchy of Controls is shown in order of effectiveness:

1) Elimination

2) Substitution

3) Engineering Controls

4) Administrative Controls

5) Personal Protective Equipment

This hierarchy of controls is widely accepted and will serve as the basis for the mitigation methods described within in this manuscript. Typical engineering controls for poor or unhealthy IAQ include ventilation (exchanging indoor air with clean outdoor air), air cleaning (filtering and recirculating indoor air) and airflow (directionally moving air). Implementation of these engineering solutions will, over time, result in improvements that are more enduring and effective at improving IAQ than administrative controls (such as reducing work hours) or the use of personal protective equipment (PPE).

\section{A Practical Approach}

The proposed method for addressing an air quality concern (Figure 1) follows the OSHA Hazard Prevention and Control Guidelines previously introduced (OSHA, 2016). The first step is to gather specific information about the indoor space through surveys: a visual survey of the space, initial testing and characterization of the indoor air, and a functional survey on the use of the indoor area. The survey inputs inform the quality analysis and eventual selection of appropriate 


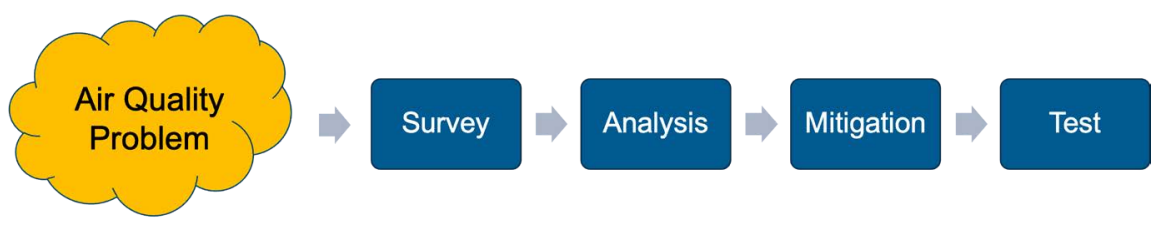

Figure 1. Practical workflow for indoor air quality management.

controls for the specific problem and space. Once the selected controls are implemented, the IAQ testing is repeated to verify improvement.

\section{Survey Considerations}

Evaluating IAQ begins with documenting specifics of the indoor space including its physical characteristics, the way people inhabit and use the space, the existing air quality controls, the typical air quality, or concerns. Specific information is required from the inhabitants of the space and its administrators (Figure 2(a)), as well as a description of the current air quality engineering controls including the ventilation system and any existing air filtration or purification systems. A complete account of any existing air exchange system should include the MERV filtration level of any filters used, and an understanding of its basic airflow supply to all spaces which are expressed in both cubic feet per minute (or CFM) and in air exchanges per hour (ACH).

Questions on ventilation include the possibility of opening doors and windows or increasing the CFM and $\mathrm{ACH}$ that can be achieved. Ventilation solutions that use outdoor air must consider outdoor air temperature and the likelihood that inhabitants may override or circumvent air quality engineering solutions. Relevant information about space usage includes how long people tend to stay in the space and their typical activities, with special attention to actions that may affect air quality, such as cooking or singing. For instance, loud singing produces more exhaled particles then talking at normal volumes (Asadi et al., 2019), so rooms that are used for choral practice may contain a much larger amount of human respiratory emissions when compared to rooms with a single teacher speaking to a class of students. Important details about existing filtration and purification systems include their cleaning capacity in $\mathrm{ACH}$ and the location of the systems with respect to the existing airflow. The survey will also gather information on location specific issues such as the source of existing air quality hazards, local chemistry, and air dynamics (Figure 2(b)).

Local conditions can also have a significant impact on IAQ. For example, carbon monoxide $(\mathrm{CO})$ is a contaminant introduced by incomplete combustion from wildfires or from dirty furnaces or water heaters and can cause hypoxemia or lead to death if not mitigated. CO has a vapor density that is slightly lighter than air, so it mixes and diffuses quickly throughout an indoor airspace which also means the outdoor environment can affect the indoor air space. Local chemistry and physical dynamics might also include effects from larger particulate matter (PM10), ozone $\left(\mathrm{O}_{3}\right)$, nitrogen dioxide $\left(\mathrm{NO}_{2}\right)$, and sulfur dioxide $\left(\mathrm{SO}_{2}\right)$ as shown in Figure 3, the output of a regional weather monitoring app installed on 


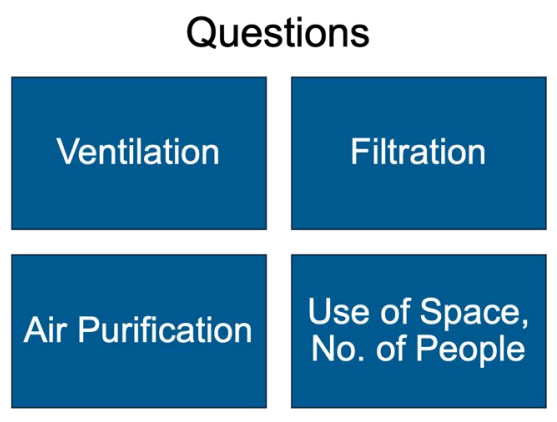

(a)

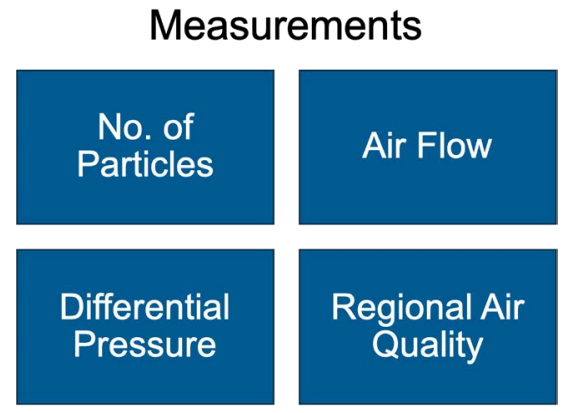

(b)

Figure 2. (a) Information about the space required for IAQ analysis and control planning, and (b) measurements taken during air quality testing before and after application of controls.

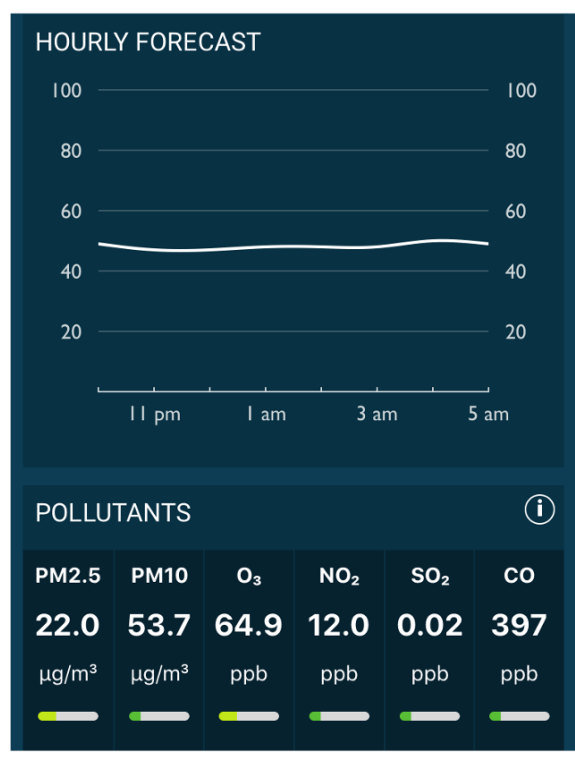

(a)

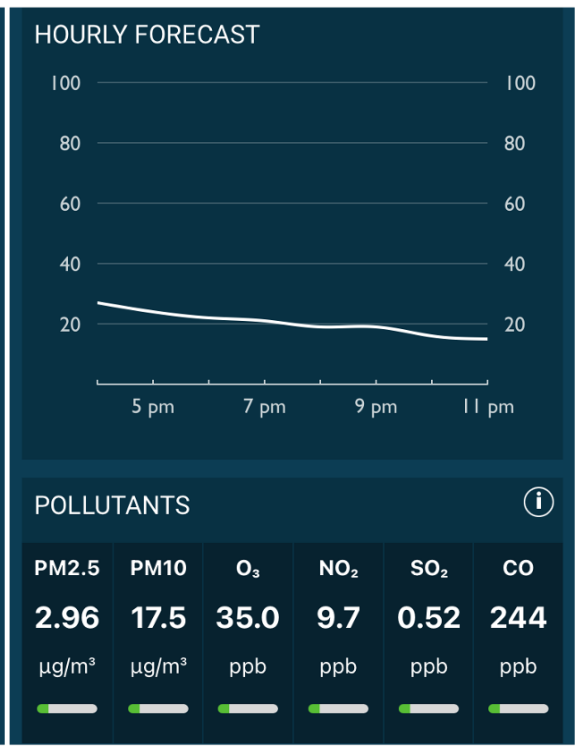

(b)

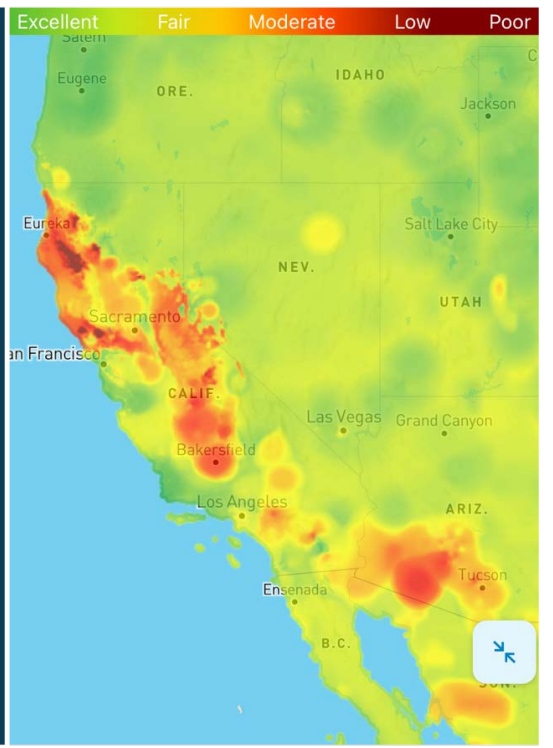

(c)

Figure 3. Example of regional air quality monitoring using WeatherBug app and its data feeds showing (a) marginal air quality, (b) clean air day with an hourly forecast that declines with evening temperature changes, (c) impact on regional air quality from September 2020 wildfires in the Western U.S.

a smartphone. Since outside air quality data is not the focus of this paper, more information on air pollution can be found at the U.S. Environmental Protection Agency (U.S. EPA, 2014a).

\section{Analysis and Mitigation Tools}

Solutions for improving IAQ will vary widely along with the indoor spaces and their associated environmental factors. A mitigation guide to improve IAQ should adapt the best available scientific and engineering knowledge to the wide range of typical indoor spaces and environmental contexts. The mitigation guide will have its broadest impact when designed for use and understanding by the layperson rather than an expert.

One of the findings of our experiments is that existing tools available to sup- 
port IAQ improvements and the selection of appropriate mitigations are not holistic in nature. IAQ mitigation aids that were created to reduce the risk of COVID-19 transmission indoors include the COVID-19 Airborne Transmission Tool (Jimenez, 2020), the COVID-19 Indoor Safety Guideline (Khan et al., 2020), and the COV-IRT Exposure Tool (Schimmoller et al., 2020). While these are powerful tools, they are difficult to apply without some background knowledge on aerosols, fluid dynamics, or airborne pathogen transmissions. These tools are also based on individual risk models that may not be optimal for the specific indoor air space use-case. For example, several tools may only consider an airborne contaminant which has equalized through the indoor area, and only offer a mitigation of increased air exchanges or improved filtration. Yet they do not account for direct emissions of infectious pathogens from person to person as represented by an aerosol cloud dispersion, and do not consider the disruption of aerosol dispersion or localized air purification. In addition, there are several IAQ models that consider the propagation of potentially infectious airborne contaminants, however, the selection of which analysis method to use for understanding risk in the field is not clear. Furthermore, subject matter expert opinion can introduce subjectivity and variance to the analysis, and for a particular complex indoor air space should be considered only as a good hypothesis that requires field testing to verify the suggested mitigations. Consequently, these gaps identify an opportunity to develop a software hybrid utilization of aerosol or risk models within a decision support software tool that can be used on tablet computers in the field.

\section{Mitigations: The Selection of Indoor Air Quality Controls}

Considering human factors and the OSHA hierarchy of controls, IAQ mitigations and controls must be based on quantifying the risk from the site survey and testing the hypothesis. Subsequently, we outline several IAQ engineering controls that have minimal dependency on human factors. The overall goal of these controls is to reduce or eliminate exposure to air pollutants or contaminants at target locations. In the case of infectious pathogens such as seasonal influenza measles, SARS-CoV-2, or tuberculosis that have a potential airborne transmission mechanism, the public health goal is to disrupt the chain of transmission. Table 1 provides a simple list of mitigation strategies and common options for improving indoor air quality.

The selection of the IAQ control needs to match the identified hazard. This sometimes requires a layered approach. For example, carbon monoxide and ozone are noxious gases that quickly diffuse throughout an air space. Emplacing barriers or diverting air flows will be ineffective at controlling gaseous diffusion. In contrast, air flow diversions can be used to great benefit on aerosols or particulate matter proximate to the initial dispersion. For example, placing plexiglass or plastic barriers between workstations and the wearing of face shields are examples of controls that offer some initial mitigation but must also be supplemented 
Table 1. Example of mitigation strategies and common options for improving indoor air quality.

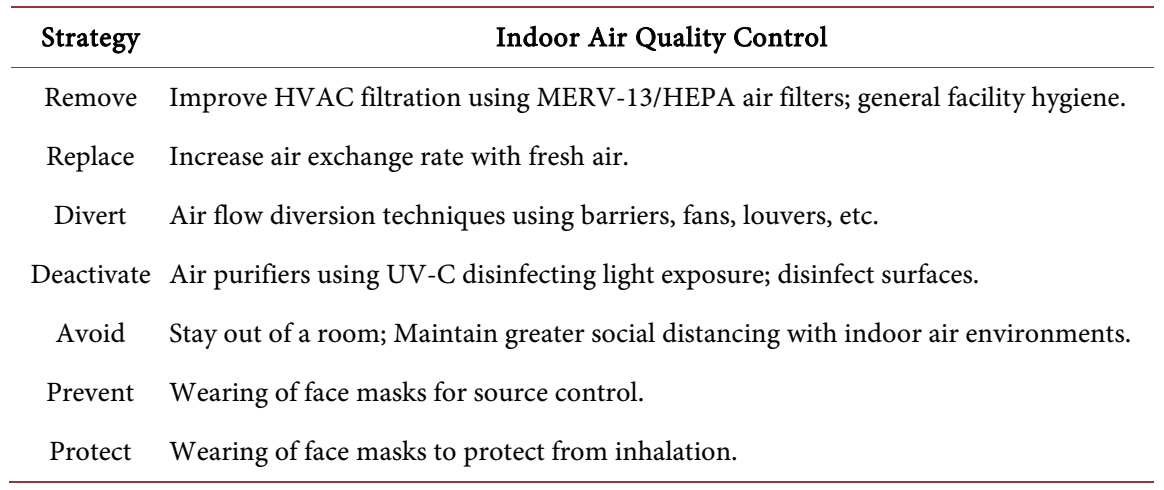

by additional layers of IAQ controls. In another example, smaller particles ( 2.5 $\mu \mathrm{m}$ and smaller) will eventually diffuse into the air space, thus requiring secondary mitigation of air exchanges and filtration which then remove the fine particles.

One potential option to reduce airborne contaminants is portable air purifiers that have an internal circulation fan, HEPA filtration, and either an electrostatic or UV-C disinfection mechanism. An important consideration when using these devices as an engineering control is to understand how the circulation fan will divert some of the local airflow. The diversion can be good or bad depending on the air quality hazard. In the case of airborne infectious pathogens, suboptimal placement of the air purifier could draw nearby contaminants into a person's local airspace and increase the hazard. Considering the concept of disrupting exposure and airflows, the air filtration unit should be placed such that it creates air flows that move continuously away from people's faces. In some instances, this might be a floor location, in other situations a ceiling mounted duct or simply an alternate location between people could be effective.

Other IAQ controls include administrative policies to address human factors, such as limiting the number of people in a room or increasing social distancing. These administrative policies are often necessary but rarely sufficient. In our field experimentation (Edwards et al., 2020; MITRE, 2020), we observe that smaller aerosolized particles will spread throughout an entire air space without mitigations. The results indicate that limiting occupants or increasing social distancing in shared air spaces may only offer some benefit and additional layers of IAQ controls will be needed to sufficiently reduce the risk of disease transmission.

\section{Reduced Cost Field Testing}

One of the most important activities to ensure IAQ is to test mitigations as implemented. Given budget constraints of many municipal organizations, it is imperative to consider effective but lower cost methods. Basic field tests help determine if a mitigation actually works in the specific indoor air environment and ensures that the critical systems are effective. By selecting optimal-cost test me- 
thod and tools, more expansive testing can be conducted throughout a community. The remainder of this section will describe typical test equipment and methods of test that aid in cost-effective field testing of indoor air quality and is based on our team's field experience.

\subsection{Portable Field Test Kits}

A field test kit must have the necessary items to check for various air quality issues and provide differential data to quantify the improvements or mitigations to IAQ. Differential data analysis requires computational data logs, either intrinsic to the device or through connection to a computer, and aid it testing dynamic environments over time. In addition, field test kits must also be portable in a hard protective case that is reasonably easy to carry and fits in common sizes of staff vehicles; there are many options from manufacturers such as Pelican, SKB, and Case Club. The kits must also be cost-effective; achieved by selecting the scientific test equipment with the lowest cost technically acceptable functionality, reliability, and serviceability.

\subsubsection{Particle Counters}

Particle monitoring sensors (PMS) and particle counters are essential test devices. They allow a baseline particle count measurement and give a quantification of existing air pollutants at locations inside a facility or vehicle. They also allow for a PM2.5 or PM10 standard air quality measurement (U.S. EPA, 2016a) and a raw particle count for capturing the dispersion of a test aerosol cloud. Improvements to IAQ are compared with baseline measurements by using differential methods such as comparing the differences between particle count areas under curve or using other statistical methods.

Many commercially available options exist for PMS devices; however, an industrial grade sensor is recommended. Industrial grade model utilizes a photometer-based sensor which offers high sensitivity and minimal false positives at a cost ranging from $\$ 1500$ to $\$ 4500$ USD each unit. There are several manufacturers of these devices (Lighthouse Worldwide Solutions, n.d.; Particles Plus, Inc., n.d.; TSI Incorporated, n.d.). Another important feature is that industrial grade sensors can be NIST calibrated annually to maintain their accuracy, and also offer internal data storage and networked or USB connections to capture and analyze the time-series data (necessary for testing aerosol cloud dispersion and mitigations).

An alternative is the ultra-low-cost non-industrial PMS device, which uses a laser light scattering detector. This reduces reliability and is more subject to false positives (Pariseau, 2019), however, the cost of light scattering sensors is typically less than $\$ 100$ USD per unit and still offers a rough estimation of the air quality. In addition, the low-cost sensor typically requires additional embedded electronics development to enable time-series data collection. The best example from extensive low-cost academic use is the Plantower PMS5003 which is usually packaged with a display screen and basic user mode button (Sayahi et al., 
2019: p. 50). These ultra-low-cost PMS can be useful for surveillance monitoring by local staff.

\subsubsection{Aerosol Test Agent}

Aerosol test agents are used to check the propagation and dispersion within an air space as well as the effectiveness of any IAQ improvements using ventilation, filtration, and other mitigations. When selecting test aerosols, it is important to consider human safety, aerosol particle sizes, and the chemical attributes previously described. The test agent must also generate sufficient particles for the sensors to detect small concentrations within the total air volume and will require a mechanism of delivery to initiate the aerosol dispersion.

The ideal safe test agents are aerosolized Potassium Chloride $(\mathrm{KCl})$ or Sodium Chloride $(\mathrm{NaCl})$ solution with distilled water. Both of these salt products are safe for human consumption or aerosolization in moderate concentrations (Fox et al., 2011; Nelson et al., 2013). When either solution is nebulized, the water evaporates when dispersed into air and allow the salts to recrystallize with a variety of particle sizes making them an ideal agent representing a variety of pollutants. Other test agents such as smoke detector test aerosols are not appropriate to use for IAQ testing because they typically use a mixture of isobutane, butane and propane which are flammable agents that disperse quickly into the air (CRC Industries, 2020; HomeHSI Fire Safety, 2020).

The American Society of Heating, Refrigeration and Air-conditioning Engineers (ASHRAE) recommends KCL as the standard HVAC test agent because it has a more stable generation of particles as it is not as affected by relative humidity $(\mathrm{RH})$ including the temperature component of RH (ANSI/ASHRAE, 2017). In contrast, the National Institute for Occupational Safety and Health (NIOSH) selected $\mathrm{NaCl}$ as its standard test agent for respiratory protective equipment such as the N95 masks (NIOSH, 2019). One of the considerations is that $\mathrm{NaCl}$ particle generation will be affected by temperature and relative humidity inside the test environment. Either $\mathrm{KCl}$ or $\mathrm{NaCl}$ solutions will provide valuable dispersion data and are safe in air spaces frequented by people.

Our experiments used $10 \% \mathrm{NaCl}$ by weight to $90 \%$ distilled water to generate particle counts sufficient for the air volume of transit buses when measured by a Particles Plus 8306 sensor (MITRE, 2020). KCl will have its own unique concentration needed for generating sufficient particles. For smaller indoor air volumes, a lower concentration may be indicated and, separately, purging of the air after a test is required. Both $\mathrm{NaCl}$ and $\mathrm{KCl}$ water-based solutions can be aerosolized with a simple cosmetic atomizer, small hobby air brush (venturi effect pickup tube), or the use of an over-the-counter medical nebulizer. Once aerosolized, the solution can be delivered into the indoor test environment with a mechanical air volume from a medical bag resuscitator (Laerdal Medical, 2020) or a manual high-volume camping air pump, which is commonly available at retail outdoor stores (Intex Recreation Corp., 2020), both of which emulate an adult's exhalation. 


\subsubsection{Carbon Dioxide and Other Gas Sensors}

Carbon dioxide $\left(\mathrm{CO}_{2}\right)$ and other gas sensors have some usefulness for IAQ, however, they have some limitations compared to particulate matter sensors. $\mathrm{CO}_{2}$ in low concentrations is a safe representation of the physical gas state of some pollutants which can be noxious odors, corrosive agents, or asphyxiants. However, $\mathrm{CO}_{2}$ and other gas tend to be lighter than air and diffuse or equalized more quickly through normal air environments compared to that of particulate matter or aerosols. This means that the use of $\mathrm{CO}_{2}$ and sensors for testing a ventilation system's effectiveness will not fully represent the system's ability to exchange air as some gas will dissipate elsewhere. While $\mathrm{CO}_{2}$ sensors have typically been used for specialty work areas that have hazardous asphyxiants such as fire suppression systems, cryogenics, or other areas where $\mathrm{CO}_{2}$ biproducts may exist, they have also been used in research as a measurement of human respiration gas exchange in public environments and then as a basis for estimating respiratory transmission risk (Andrews et al., 2013; Wood et al., 2014). In addition, various international public events are using $\mathrm{CO}_{2}$ sensor levels to offer participants a visual real time risk indicator of rebreathing exhalation aerosols given SARS-CoV-2 pandemic concerns (Nonaka, 2020). Many industrial organizations that deal with gaseous products have test devices that account for $\mathrm{CO}_{2}$ as well as other dangerous gases, however, those are designed to check for higher level dangerous conditions rather than the lower grade pollutant.

\subsubsection{Airflow Sensors}

Characterizing and understanding the airflow in an indoor environment is extremely important. Airflow and differential pressures have a direct impact on the movement or evacuation of airborne contaminants. These details of airflow allow decision makers to best position auxiliary risk mitigation equipment.

Anemometers are the typical sensors used to characterize airflow in an indoor environment. The two most common types are hot wire anemometers and vane anemometers. Hot wire anemometers operate based on a very thin wire being cooled as a result of airflow and are extremely accurate. Hotwire devices are also the preferred choice for low air speeds and in open environments where the directionality of the airflow is typically unknown, both of which are typical of indoor environments. In contrast, vane anemometers are a mechanical device which convert the rotating motion of a propeller into a linear air speed and more suited for capturing mean airflow in a system where directionality effects are minimal. An example would be a long, straight section in HVAC ducting. A high quality, accurate anemometer with wireless data logging capabilities is the HHF1001R-W model from Omega which also offers an extendable probe to reach ceiling or difficult to reach place (Omega, 2020).

Manometers, such as the Omega HHP886U, are typically used to characterize pressure drop or differential pressure in a system. One critical application for manometers is the measurement of and calibration of a negative pressure room used for the medical treatment of respiratory disease patients (Stewart et al., 2020; TSI, 2020). Another application is during testing of a retrofit air filter ap- 
plication; some air filters with improved filtration are more restrictive to airflow and may require measurement if they will strain the HVAC system. These devices are typically used by HVAC technicians but are recommended mainly for the special applications or environments that require an understanding of differential pressures.

\subsection{Test Methods and Data Collection}

With the simplified process described in this manuscript, there are two times to perform field testing. The first is done as part of the survey to gather detailed information about the indoor air space and its baseline measurements. Part of the survey testing requires characterization of the environment through sensor deployment at multiple locations. Initial survey testing should include all of the following areas:

- Inlet (supply air) and outlet (return air) vents

- Close proximity to standalone air purifiers

- Windows and doors

- Discrete locations within the environment

- High frequency locations, such as the following:

- Bedrooms in a nursing home

- Desks in school classrooms

- Desk locations in open plan offices

- Indoor areas normally used by people but without apparent ventilation

However, the final improvement testing may require only a few select locations. The final testing for evaluating mitigations also requires a repeatable scientific approach and careful documentation of the layout of the indoor air environment as well as sensor positioning and test conditions. Five types of measurements (Table 2) are helpful to determine the appropriate engineering controls and mitigations and also quantitatively characterize the air quality improvement.

Table 2. Summary of field test measurements.

\begin{tabular}{|c|c|c|c|}
\hline Measurement & Device or Sensor & Data Observations & $\begin{array}{c}\text { Units of } \\
\text { Measurement }\end{array}$ \\
\hline Particle Count & $\begin{array}{l}\text { PMS, Particle } \\
\text { Counter }\end{array}$ & $\begin{array}{l}\text { Raw particle count mode of sensor. Helps } \\
\text { determine aerosol dispersion and } \\
\text { effectiveness of mitigations during a test }{ }^{\mathrm{a}}\end{array}$ & $\begin{array}{l}\text { Particle counts per } \\
\text { sample rate }\end{array}$ \\
\hline $\begin{array}{c}\text { Particle } \\
\text { Concentration }\end{array}$ & $\begin{array}{l}\text { PMS, Particle } \\
\text { Counter }\end{array}$ & $\begin{array}{l}\text { Concentration mode of the sensor. Used for } \\
\text { general air quality monitoring }\end{array}$ & $\begin{array}{l}\text { Count per } \mathrm{ft} 3 \text { or } \mathrm{L} \text {, } \\
\text { PM2.5, PM10 }\end{array}$ \\
\hline Airflow & Anemometer & $\begin{array}{l}\text { Air velocity, temperature. Used to } \\
\text { characterize the speed and directionality of } \\
\text { airflow at various locations }{ }^{b}\end{array}$ & $\mathrm{~m} / \mathrm{s}, \mathrm{FPM},{ }^{\circ} \mathrm{C},{ }^{\circ} \mathrm{F}$ \\
\hline $\begin{array}{l}\text { Differential } \\
\text { Pressure }\end{array}$ & Manometer & $\begin{array}{l}\text { Compares the pressure between two } \\
\text { sampling locations for HVAC balancing or } \\
\text { healthcare negative pressure isolation rooms }\end{array}$ & $\begin{array}{l}\text { Psi, mbar, or } \\
\qquad \mathrm{mmH}_{2} \mathrm{O}\end{array}$ \\
\hline $\begin{array}{l}\text { Regional Air } \\
\text { Quality }\end{array}$ & $\begin{array}{l}\text { Weather/IAQ } \\
\text { smartphone app }\end{array}$ & $\begin{array}{l}\text { Gives region air quality data, pollen, and } \\
\text { other pollutants }\end{array}$ & $\begin{array}{l}\mathrm{PM} 2.5, \mathrm{PM} 10, \mathrm{O}_{3}, \\
\mathrm{NO}_{2}, \mathrm{SO}_{2}, \mathrm{CO}\end{array}$ \\
\hline
\end{tabular}




\section{Observations from Recent Indoor Air Quality Studies}

To establish a technical basis for the approach described in this paper, we offer some lessons learned from our recent field studies on indoor air quality. Over a several-month period, we conducted over 190 experimental tests on aerosol dispersion and IAQ mitigations related to the COVID-19 pandemic, which resulted in 79.9 million points of real time data. These experiments considered the effect of forty different fabric masks on controlling dispersion from a cough, and also observe aerosol dispersion on school buses and transit buses. The goal was to quantitatively determine low-cost mitigations for air quality improvements and reduce risks of exposure to airborne infectious pathogens (Edwards et al., 2020; MITRE, 2020). Our field experiments used IAQ particle counters, air flow measurements, computational fluid dynamic simulations comparing to real world data, and correlated airflow to vehicle velocity. Throughout these experiments, we established novel analytical methods to easily measure the effectiveness of reducing particle dispersion.

While our recent experiences used numerous high-fidelity sensors and scientific methods to holistically understand air quality and aerosol dispersion, the observations made are broadly applicable outside of the scientific community. First, ventilation and airflow inside various environments is usually turbulent. Ventilation and air exchanges provided by fans or HVAC systems, as well as the opening and closing of doors, movement of people, windows, and plenum air movement all create a non-steady air environment. This means that any testing or sampling should consider measurement over a period of time to better understand the cumulative effect of improvements despite any transient air turbulence.

Second, air quality measurement is not precise. Between each experimental test we sometimes observed variances of greater than fifty percent of the statistical mean depending on current environmental conditions. The primary reason is that the fluid dynamics of air and its contaminants depend on temperature, humidity, intrinsic airflows (laminar or turbulent), contaminant aerosol composition, surface friction constraints, and several other factors that can change within a specific time period. Consequently, all air quality measurements must consider the relativity to a given time period or set of conditions. However, from each of the relative tests and measurements we learn valuable information on the overall system response and any air quality improvements, and the resulting trendlines provided definitive basis for inferences and observations. The important take-away is to be cautious on drawing comparative conclusions from data of multiple time periods.

Third, it is essential to understand the chemistry basics and dynamics of the specific air quality contaminants of concern. Particulate matter around $2.5 \mu \mathrm{m}$ in size and smaller (PM2.5) are considered fine inhalable particles and can be generated from fine dust or potentially infectious aerosols from human exhalation. Depending on its composition of organic material, minerals, water, its dynamic 
behavior such as dispersion pattern and time aloft will vary (Atkinson, 2009; Atkinson et al., 2009; Bourouiba, 2020). Our observation of using NIOSH standard test agent of $\mathrm{NaCl}$ nebulized in water was that the recrystallization process particle generation has inconsistencies due to environmental temperature and humidity conditions, but it is still a safe test agent that generates sufficient particles to measure air quality mitigations methods for several particle sizes.

Finally, we observed that improvements to air quality can be measured in multiple ways that may not require high-fidelity experimentation. While establishing a physics fluid dynamics model requires detailed data and numerous sensors, approximating the average improvements for an indoor environment only requires a few measurements. An indoor environment follows more of an imperfect closed-loop model for air flow and contaminants where the overall building air tends to be static unless disrupted by door openings, ductwork, or temperature and pressure differentials. This means the generalized effect of an improvement may be measured by only a few sensors at select locations that are less susceptible to the localized turbulence as previously described.

A summary of the key observations is provided below:

- Ventilation and airflow inside various environments are usually turbulent.

- Testing or sampling should consider measurement over a period of time to better understand the cumulative effect of improvements despite any turbulent air.

- Air quality monitoring or measurement must consider the relativity to a given time period or set of conditions. Caution on drawing comparative conclusions from data of multiple time periods.

- Understanding the basic chemistry and dynamics of the specific air quality contaminants is important. For example, the use of gaseous test agents like $\mathrm{CO}_{2}$ has very different dispersion or diffusion dynamics than particulate matter.

- Improvements to air quality can be measured in multiple ways that may not require high-fidelity experimentation.

\section{Conclusion}

We have presented a practical approach for municipalities, counties, and other administrative organizations to implement an indoor air quality program for public health and safety. The simplified operational model for conducting the indoor air quality surveys, analysis, and testing can be reliably executed by non-specialist government employees, community volunteers (similar to many smoke detector programs) or by local contractors (e.g., home inspectors) who are informed on the steps of this IAQ method. The outcome of this simplified method based on the OSHA hazard control process can help stewards of indoor environments reduce the risks to population health and well-being caused by pollutants or airborne pathogens. Affordable and effective IAQ management techniques such as the one we have described are essential today as the current 
pandemic evolves, and will be increasingly valuable as new and consequential airborne threats emerge.

\section{Acknowledgements}

This work was supported by independent research and development funding provided by the author's organization, The MITRE Corporation. @2021 The MITRE Corporation. All Rights Reserved. Approved for Public Release; Distribution Unlimited. Public Release Case Number 20-00068-2.

\section{Conflicts of Interest}

The authors declare no conflicts of interest regarding the publication of this paper.

\section{References}

Acharya, B., \& Thapa, K. (2016). Indoor Staying During Winter Season Makes People More Susceptible to Flu. Journal of Nepal Health Research Council, 14, 69-70.

Andrews, J. R., Morrow, C., \& Wood, R. (2013). Modeling the Role of Public Transportation in Sustaining Tuberculosis Transmission in South Africa. American Journal of Epidemiology, 177, 556-561. https://doi.org/10.1093/aje/kws331

ANSI/ASHRAE (2017). ANSI/ASHRAE Test Standard 52.2, Appendix A4. https://www.ashrae.org/technical-resources/standards-and-guidelines

Asadi, S., Wexler, A. S., Cappa, C. D., Barreda, S., Bouvier, N. M., \& Ristenpart, W. D. (2019). Aerosol Emission and Superemission during Human Speech Increase with Voice Loudness. Scientific Reports, 9, Article No. 2348. https://doi.org/10.1038/s41598-019-38808-Z

Atkinson, J. (2009). Natural Ventilation for Infection Control in Health-Care Settings. Geneva: World Health Organization. https://www.ncbi.nlm.nih.gov/books/NBK143284

Atkinson, J., Chartier, Y., Pessoa-Silva, C. L., Jensen, P., Li, Y., \& Seto, W.-H. (2009). Annex C Respiratory Droplets. In Natural Ventilation for Infection Control in Health-Care Settings (pp. 77-82). Geneva: World Health Organization.

https://www.ncbi.nlm.nih.gov/books/NBK143281

Bourouiba, L. (2020). Turbulent Gas Clouds and Respiratory Pathogen Emissions: Potential Implications for Reducing Transmission of COVID-19. JAMA, 323, 1837. https://doi.org/10.1001/jama.2020.4756

Charlotte, N. (2020). High Rate of SARS-CoV-2 Transmission Due to Choir Practice in France at the Beginning of the COVID-19 Pandemic. https://doi.org/10.1101/2020.07.19.20145326

CRC Industries (2020). Smoke Test ${ }^{\oplus}$ Brand Smoke Detector Tester, 2.5 Wt Oz-02105. https://www.crcindustries.com/products/smoke-test-174-brand-smoke-detector-tester2-5-wt-oz-02105.html

Edwards, N. J., Widrick, R., Potember, R., \& Gerschefske, M. (2020). Quantifying Respiratory Airborne Particle Dispersion Control through Improvised Reusable Masks: The Physics of Non-Pharmaceutical Interventions for Reducing SARS-COV-2 (COVID-19) Airborne Transmission. Journal of Nanotechnology and Nanomaterials, 1, 116-128. https://doi.org/10.33696/Nanotechnol.1.015

Fox, L. M., Foushee, J. A., Jackson, D. J., \& Watson, H. (2011). Visual Compatibility of 
Common Nebulizer Medications with 7\% Sodium Chloride Solution. American Journal of Health-System Pharmacy, 68, 1032-1035. https://doi.org/10.2146/ajhp100335

Guenther, T., Czech-Sioli, M., Indenbirken, D., Robitailles, A., Tenhaken, P., Exner, M., Ottinger, M., Fischer, N., Grundhoff, A., \& Brinkmann, M. (2020). Investigation of a Superspreading Event Preceding the Largest Meat Processing Plant-Related SARS-Coronavirus 2 Outbreak in Germany (SSRN Scholarly Paper ID 3654517). Social Science Research Network. https://doi.org/10.2139/ssrn.3654517

Hamner, L. (2020). High SARS-CoV-2 Attack Rate Following Exposure at a Choir Practice-Skagit County, Washington, March 2020. Morbidity and Mortality Weekly Report, 69, 606-610. https://doi.org/10.15585/mmwr.mm6919e6

HomeHSI Fire Safety (2020). SmokeCheck ${ }^{\circledast}$. HomeHSI Fire Safety. https://www.hsifiresafety.com/product/smokecheck

Intex Recreation Corp. (2020). Intex Manual Air Pumps. https://intexcorp.com/products/pumps/manual-pumps

Jimenez, J.-L. (2020). COVID-19 Airborne Transmission Tool. Boulder, CO: Cooperative Institute for Research in Environmental Sciences at the University of Colorado Boulder. https://cires.colorado.edu/news/covid-19-airborne-transmission-tool-available

Khan, K., Bush, J. W. M., \& Bazant, M. Z. (2020). COVID-19 Indoor Safety Guideline. https://indoor-covid-safety.herokuapp.com

Kwon, K.-S., Park, J.-I., Park, Y. J., Jung, D.-M., Ryu, K.-W., \& Lee, J.-H. (2020). Evidence of Long-Distance Droplet Transmission of SARS-CoV-2 by Direct Air Flow in a Restaurant in Korea. Journal of Korean Medical Science, 35, e415.

https://doi.org/10.3346/jkms.2020.35.e415

Laerdal Medical (2020). The BAG II ${ }^{\circledast}$ Disposable Resuscitator. Laerdal Medical. https://laerdal.com/us/products/medical-devices/airway-management/the-bag-ii-dispo sable-resuscitator

Lighthouse Worldwide Solutions (n.d.). Lighthouse Worldwide Solutions. https://www.golighthouse.com/en

MITRE (2020). Face Masks, Open Windows on Buses Reduce Potentially Infectious Particles in the Air. The MITRE Corporation. https://www.mitre.org/news/press-releases

Nelson, A. J., Page, M. A., Ginsberg, M. D., \& Rood, M. J. (2013). Bench-Scale Aerosol Filtration Test System and Evaluation of an Acoustic Bioaerosol Removal Device for Indoor Air Streams. Aerosol Science and Technology, 47, 1285-1292.

https://doi.org/10.1080/02786826.2013.835026

NIOSH (2019). Determination of Particulate Filter Efficiency Level for N95 Series Filters against Solid Particulates for Non-Powered, Air-Purifying Respirators Standard Testing Procedure (STP) (TEB-APR-STP-0059). Washington DC: National Institute for Occupational Safety and Health. https://www.cdc.gov/niosh/npptl/stps/pdfs/TEB-APR-STP-0059-508.pdf

Nonaka, R. (2020). Screens Showing $\mathrm{CO}_{2}$ Level Set Up at Venues to Lessen Virus Risk. The Asahi Shimbun. http://www.asahi.com/ajw/articles/13832094

Omega (2020). Wireless Handheld Air Temperature \& Velocity Meter. https://www.omega.com/en-us/test-inspection/handheld-meters/anemometers/hhf100 0 -series/p/HHF1001R-W

OSHA (2016). Recommended Practices for Safety and Health Programs: Hazard Prevention and Control (OSHA 3885). Occupational Safety and Health Administration. https://www.osha.gov/shpguidelines/hazard-prevention.html

OSHA (2020). Indoor Air Quality. https://www.osha.gov/indoor-air-quality 
Pariseau, D. (2019). Air Quality Instrumentation: Part III-Particle Mass (PM) Estimation.

https://particlesplus.com/air-quality-instrumentation-part-iii-particle-mass-pm-estima tion

Particles Plus, Inc. (n.d.). https://particlesplus.com

Sayahi, T., Butterfield, A., \& Kelly, K. E. (2019). Long-Term Field Evaluation of the Plantower PMS Low-Cost Particulate Matter Sensors. Environmental Pollution, 245, 932-940. https://doi.org/10.1016/j.envpol.2018.11.065

Schimmoller, B., Isbell, M., Dutta, S., Beheshti, A., \& Archer, T. (2020). A Simple-to-Use Tool (BETA Version) for Comparing Group Exposure to SARS-COV-2. COV-IRT. https://www.cov-irt.org/exposure-assessment-tool

Schröder-Hinrichs, J. U., Baldauf, M., \& Ghirxi, K. T. (2011). Accident Investigation Reporting Deficiencies Related to Organizational Factors in Machinery Space Fires and Explosions. Accident Analysis \& Prevention, 43, 1187-1196.

https://doi.org/10.1016/j.aap.2010.12.033

Simmons-Duffin, S. (2020). 14 States Make Contact Tracing Data Public. Here's What They're Learning. NPR.Org.

https://www.npr.org/sections/health-shots/2020/08/14/902271822/13-states-make-cont act-tracing-data-public-heres-what-they-re-learning

Snell, J. (2015). Engineered Safety: Some Key Principles and Examples (No. SAND20158963C). Albuquerque, NM: Sandia National Lab.

https://www.osti.gov/biblio/1332878

Stewart, E. J., Schoen, L. J., Mead, K., Olmsted, R. N., Sekhar, C., Vernon, W., Pantelic, J., Li, Y., Sultan, Z. M., \& Conlan, W. (2020). ASHRAE Position Document on Infectious Aerosols. ASHRAE, 24.

TSI (2020). Webinar: How to Create Temporary Negative Pressure Rooms in Times of Pandemic. https://www.tsi.com/converting-spaces

TSI Incorporated (n.d.). TSI.Com. https://tsi.com//home

U.S. CDC \& U.S. HUD (2006). Healthy Housing Reference Manual. Washington DC: U.S. Department of Health and Human Services. https://www.cdc.gov/nceh/publications/books/housing/housing.htm

U.S. EPA (2014a). Criteria Air Pollutants [Other Policies and Guidance]. US EPA. https://www.epa.gov/criteria-air-pollutants

U.S. EPA (2014b). Introduction to Indoor Air Quality [Collections and Lists]. US EPA. https://www.epa.gov/indoor-air-quality-iaq/introduction-indoor-air-quality

U.S. EPA (2016a). Particulate Matter (PM) Basics [Overviews and Factsheets]. US EPA. https://www.epa.gov/pm-pollution/particulate-matter-pm-basics

U.S. EPA (2016b). Health Effects Notebook for Hazardous Air Pollutants [Reports and Assessments]. US EPA. https://www.epa.gov/haps/health-effects-notebook-hazardous-air-pollutants

Weekes, D., Lapotaire, J. P., Persily, A., Siegel, J., Stephens, B., Walker, I., Wargocki, P., \& White, B. (2020). ASHRAE Position Document on Indoor Air Quality. ASHRAE.

Wood, R., Morrow, C., Ginsberg, S., Piccoli, E., Kalil, D., Sassi, A., Walensky, R. P., \& Andrews, J. R. (2014). Quantification of Shared Air: A Social and Environmental Determinant of Airborne Disease Transmission. PLOS ONE, 9, e106622.

https://doi.org/10.1371/journal.pone.0106622 